\title{
Gender Discrimination in Death Reportage: Reconnoitering Disparities through a Comparative Analysis of Male and Female Paid Obituaries of Pakistani English Newspapers
}

\author{
Sajid M. Chaudhry (Corresponding author) \\ Awang Had Salleh Graduate School of Arts and Sciences \\ Universiti Utara Malaysia \\ E-mail: sajid_ch@hotmail.com \\ Anne A. Christopher \\ School of Education \& Modern Languages \\ College of Arts and Sciences, Universiti Utara Malaysia \\ E-mail:althea@uum.edu.my \\ Hariharan A/L N.Krishnasamy \\ School of Education \& Modern Languages \\ College of Arts and Sciences, Universiti Utara Malaysia \\ E-mail: hn1084@uum.edu.my
}

Doi:10.7575/aiac.alls.v.5n.2p.29

Received: $14 / 02 / 2014$

URL: http://dx.doi.org/10.7575/aiac.alls.v.5n.2p.29

Accepted: 24/03/2014

\begin{abstract}
The study examines the issue of gender discrimination in the post death scenario of obituarial discourse. It aims to identify the way Pakistani newspaper obituaries recognize and project males and females after their deaths. A total of 601 paid obituaries published in a year's time span in Pakistani English newspapers were evaluated for the purpose. 10 qualitative interviews were also conducted to supplement the findings and discussion. Quantification of the data suggests that males not only get more obituaries but also get added projection when compared to females. To understand the reasons behind this varied treatment, the participants' responses were analyzed. The findings reveal that the observed differences in the death reportage of both genders do not purely fall in the line of gender discrimination. Males get situational advantage due to the factors like familial traditions, religious beliefs, cultural traditions and socioeconomic environments.
\end{abstract}

Keywords: Obituarial Discourse, Obituary Announcement, Gender Discrimination, Socio-cultural Norms, Familial Traditions, Situational Advantage

\section{Introduction}

Obituary announcements are community oriented social texts authored according to certain accepted and established social and, in many cases, religious conventions. It is widely believed that religious beliefs, cultural values and societal practices of a particular society form the basis of the language employed and content written by the writers of these socio-cultural and religiously oriented announcements. Moses and Marelli (2004, p.123) consider the obituary "a window that provides a view into a culture." Being social and cultural products, these announcements help their readers understand social realities and measure prevailing societal norms, trends and change in these practices of the societies they belong to. Researchers consider these necrology twins (obituaries and death notices) as an undisputable data source for the purpose since these "summarize what is said about and done for people immediately after death" (Haley, 1977, p. 207).

Considering the newspaper obituary a socio-cultural product, which reflects the societal norms, the current study aims at exploring the way Pakistani society remembers and honors its male and female populace in the post-death scenario of obituarial discourse. Specifically, this study examines if women get equal public recognition in obituarial literature as compared to men or if they are subject to discrimination and ostracism. This research area has been explored by many researchers during the last couple of decades. By examining the contents of newspaper obituary announcements and death notices, many attempts have been made previously to study this complex anthropological phenomenon from varying perspectives. However, still there is a scarcity of contextual understandings like how and why obituary announcements get influenced, directly or indirectly, by the societal, cultural and religious factors. The current study is an effort to cover this existing lacuna by exploring the circumstantial actualities that influence content, format and appearance of these announcements. 


\section{Literature Review}

'Gender' as a societal delineation allocates social roles to males and females based on the traditional notions of masculinity and femininity. These roles, according to Alam (2011, p.329) are determined by the socio-economic, ethnocultural and religio-political factors of the particular society. 'Discrimination' is a rejection or denial process based on the ideas of inequality (Iqbal et al., 16, p.2012). As a collective term, 'gender discrimination' refers to the negation or denial of the right of parity to a particular gender by the other in social, cultural and economic spheres of life. Historically, the phenomenon is attached to the uneven treatment females come across and the prejudicial behavior they suffer from during their life span. In wider socio-cultural perspectives, the concept refers to the practice of repudiating rights and privileges to women or sidelining them merely because of femininity. Not a single society is immune to the practice of discriminating women as compared to men. This social phenomenon of discrimination is not limited to a single or some societies of the global village but it has been observed universally. According to a World Bank report (2001, p.4) "in no region do women and men have equal social, economic and legal rights."

This existence of gender discrimination has also been taken up by researchers and scholars all across the globe. Research and academic arenas abound in multidimensional and multifaceted gender discrimination discourses. Starting from the technocratic purposes of decision making to the public policy decision making domains, governmental and non-governmental organizations are conducting or funding extensive research to gauge the certainty of the issue of gender discrimination. Academia is no exception to this. Academic discourses also have explored gender discrimination from various slants. Due to the jurisdictional limitations of the current study, the researcher summarizes the research that deals with the issue solely in post-death scenarios. In the recent past, many researchers of different societies have explored their particular social environments to reconnoiter the actuality surrounding gender discrimination in afterdeath situations. The research is primarily based on the belief that "in every society, members respond publicly in a different way to the deaths of males and females" (Haibur \& Vandagriff, 1987, p.421).

The important research available dealing with this gender-sensitive issue belongs to Kastenbaum et al. (1976), Spilka et al. (1979), Kearl (1986), Halbur and Vandagriff (1987), Maybury (1995), Eid (2002), Rodler et al. (2002) and Ogletree et al. (2005). The studies of these researchers mainly intend to gauge the representation and projection of both genders in obituarial discourses under the assumption that gender based partialities perpetuate after death. Except for the study of Eid (2002) which investigates the issue cross-culturally by comparing American, Egyptian and Iranian societies, the landscape of all other studies is predominantly American society. The findings of these researchers more or less confirm the researchers' hypotheses that gender biases follow women even beyond the grave. They converge nearly on one point that women are underrepresented in newspaper obituary announcements and death notices. Also, they observe that this post-death discriminatory societal response is a continuation of the treatment women-folk get during their life span. Such a response, in the words of Kastenbaum et al. (1976-1977, p. 351), "tends to confirm and perpetuate rather than challenge or transfigure previously existing sexual biases." This empirical study aims at adding some valuable facts and figures to the existing statistics. Its research setting encompasses Pakistani society and pivots around the similar supposition developed by the previous researchers that gender-based partialities continue after death. As there has not been any study of the domain of gender partiality in Pakistani newspaper obituaries, the researchers cannot challenge any existing findings or evaluate and verify them in different perspectives. So, the researchers hope that this research will not only provide first-hand statistics but will also serve as a source of accurate information for future researchers. Before moving ahead, it is pertinent here to look into the general treatment Pakistani women receive in day to day affairs. This will help form an idea about the viewpoints of Pakistani society about its female populace.

\section{The Pakistani Context}

Women in Pakistan comprise more than half of its total population (Iqbal et al., 16, p.2012). The Pakistani society is patriarchal in nature (Mumtaz et al., 2003, p.261). Traditional gender roles in Pakistan delineate home as the woman's place and define men as breadwinners (Alam, 2011, p.332). Based on these socially allocated roles, males are believed to be providers and the females as dependents. On the legal and constitutional front, there is no discrimination on the basis of gender and the constitution of Pakistan, through its articles 25 (1) and 25 (2), assures equality of rights and opportunities to both sexes and states that there shall be no discrimination on the basis of sex.

The issue of gender discrimination, in its conceptual concept, seems to be "heterogeneous and rather paradoxical" in the perspective of Pakistani society (Delavande \& Zafar, 2011, p.3). On the one hand, general perception is that compared to man, "woman is the passive partner in the system of nature, and as such, by virtue of possessing natural qualities of dominance, power and authority, man is superior" (Maududi, 1987, p.34). A report on the country's gender profile by the Sustainable Development Policy Institute (2008, p.viii) states that women are a marginalized gender in Pakistan and their status is not considered equal to that of men. The view point of Iqbal et al. $(2012$, p.16) is also not different. According to them gender discrimination is widespread in Pakistan and it leads to the insecurity of women in all spheres of their lives. Also, the World Bank's gender-sensitive portfolio review $(2009$, p.14) declares Pakistan as a country that "exhibits pronounced level of gender disparity".

On the other hand, quite paradoxically to the above-mentioned social and religious general perceptions and the social practices of discriminating against women, Pakistani women also enjoy quite proclaimed and powerful statuses in many of the national arenas. Pakistan's late Prime Minister Benazir Bhutto was the first ever elected female head of an Islamic state. During the last elected government (2008-2013), Fahmida Mirza and Hina Rabani Khar served as the first 
ever woman speaker of the National Assembly and the first ever woman Foreign Minister of any Islamic state respectively. In addition to the open competition, one third of Pakistan's local legislative seats and ten percent of total government jobs are solely reserved for females. In the last local government elections of 2005, forty-three thousand female councilors were elected for various District Governments. In a recent survey (March, 2013) conducted by Gallup Pakistan, 51\% Pakistani women acknowledge that they enjoy the same rights as their male counterparts. The USAID report on education status of Pakistan (2010-11, p.16) reveals that $51 \%$ of students enrolled in college level education are females. Recently, some females have started serving as fighter pilots in the Pakistan Army's Air Force wing. Again this is a unique example as this has never happened in any of Pakistan's neighboring states or in any other Islamic country of the world. The Al-Arabia news channel in one of its reports of Sunday, July 14, 2013 declared an inclusion of females in the Pakistan army as a landmark achievement for a Muslim society. The New York Times of December 26, 2010 and the Bloomberg Business Week Magazine in its September 7, 2011edition acknowledges Pakistani women's contribution to the job market and mentions that "they are doing everything from pumping gasoline and serving burgers at McDonald's to running major corporations.”

\section{Hypothesis}

Based on both sides of the above-mentioned evidences, the following hypotheses are developed;

\subsection{Null Hypothesis}

Pakistan is not a gender hostile society and Pakistani women do not suffer from ostracism in memorial discourse. Males and females get equal recognition in post-death scenario and males' obituaries do not outnumber females'. Also, a discriminatory attitude is not observed while authoring the content of obituaries of both genders.

\subsection{Alternative Hypothesis}

Pakistani society is gender unfriendly and its female population suffers from ostracism in memorial discourse. Females get less recognition in post-death scenario than males and males' obituaries outnumber females'. Also, a discriminatory attitude is observed while authoring the content of obituaries of both genders.

\section{Data}

To test the developed hypotheses, paid obituaries, published in 'The Dawn' and 'The News International' during a year's time span starting from November 2011 onwards, were collected. Both the newspapers were selected due to their "high circulation" (Malik \& Iqbal, n.d., p.1) and popularity among the general masses of Pakistan. To substantiate the findings and to understand the societal logics behind the emerging facts, ten qualitative open-ended interviews were also conducted. The interviewees were selected randomly. All of the interviewees remained involved in the authoring and printing process of the obituaries of their loved-ones.

\section{Methodology}

A mixed method approach involving both quantitative and qualitative analyses was adopted to reach the authentic deductions. To illustrate, publishing frequencies of the obituaries of both genders and the presence of their photographs were measured quantitatively. The facts that emerged from quantification and the general treatment in terms of contents and details of both the genders received in this memorial genre were then discussed qualitatively. This qualitative interrogation aims at exploring the hitherto neglected dimension of the previously conducted research about how the gender discrimination in funerary language results from the social customs, geographical norms and religious beliefs that surround human decrees as decisive factors.

\section{Results}

The total number of obituaries published during the selected one year's time span is 601 . The gender classification of these obituaries shows that out of 601 obituaries, 59\% (355) of the total are for the deceased males. The remaining 246 announcements, $41 \%$ of the total, are for the deceased females. Regarding the presence of the photos of the deceased, it appears that their inclusion is not a regular or obligatory feature of Pakistani newspaper obituary announcements. Out of the 601 published obituaries, only $8.5 \%$ of the announcements include photos of the deceased. Among them, 7.16\% are of males while $1.34 \%$ are of females. Figures 1.1 and 1.2 illustrate the results. Figure 1.1 explains the publication of the obituaries of both genders in the selected newspapers of each month of the selected time period. The second figure, 1.2 , shows the overall percentage of the obituaries of both genders. 


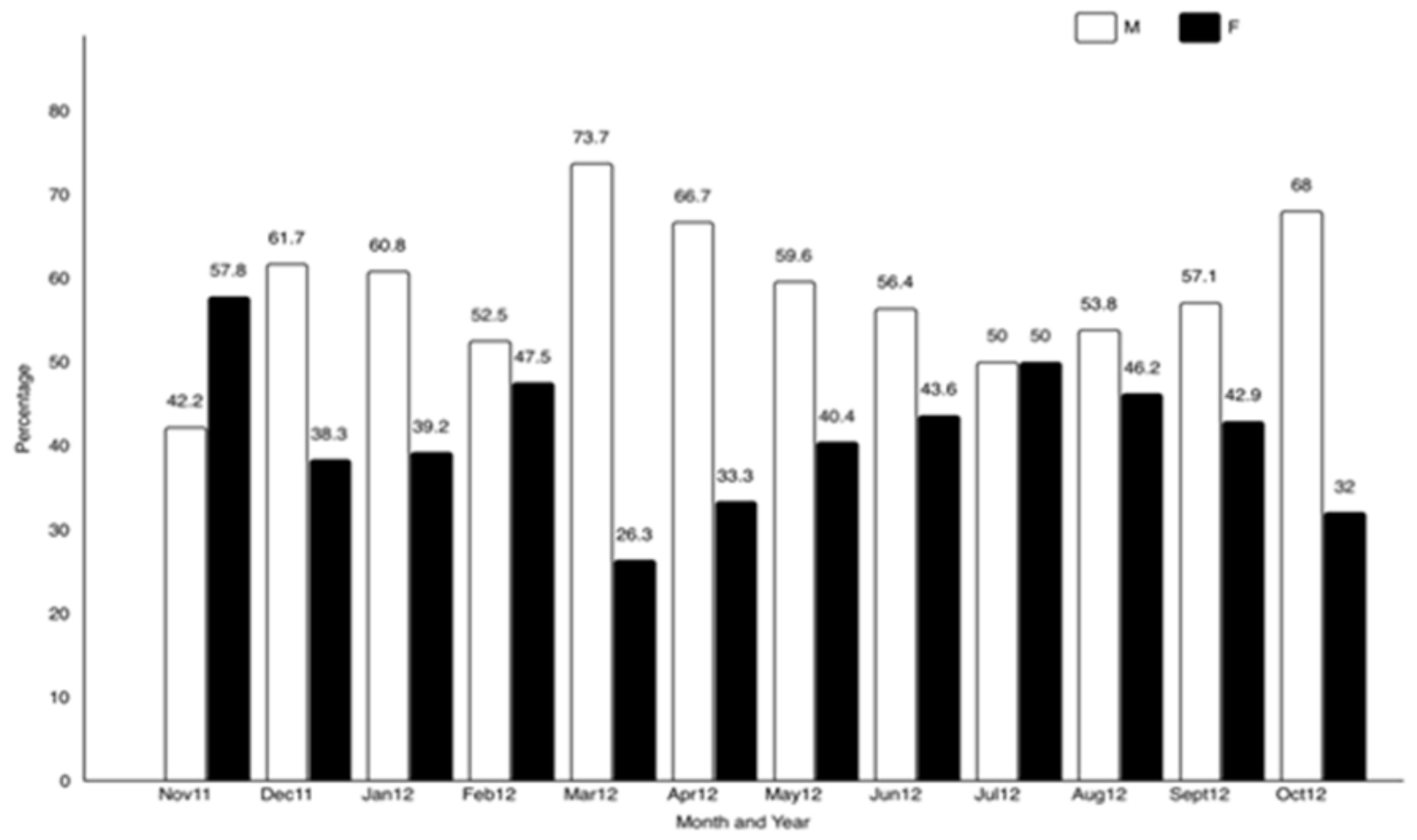

Figure 1.1 Paid Obituaries - Month and Year

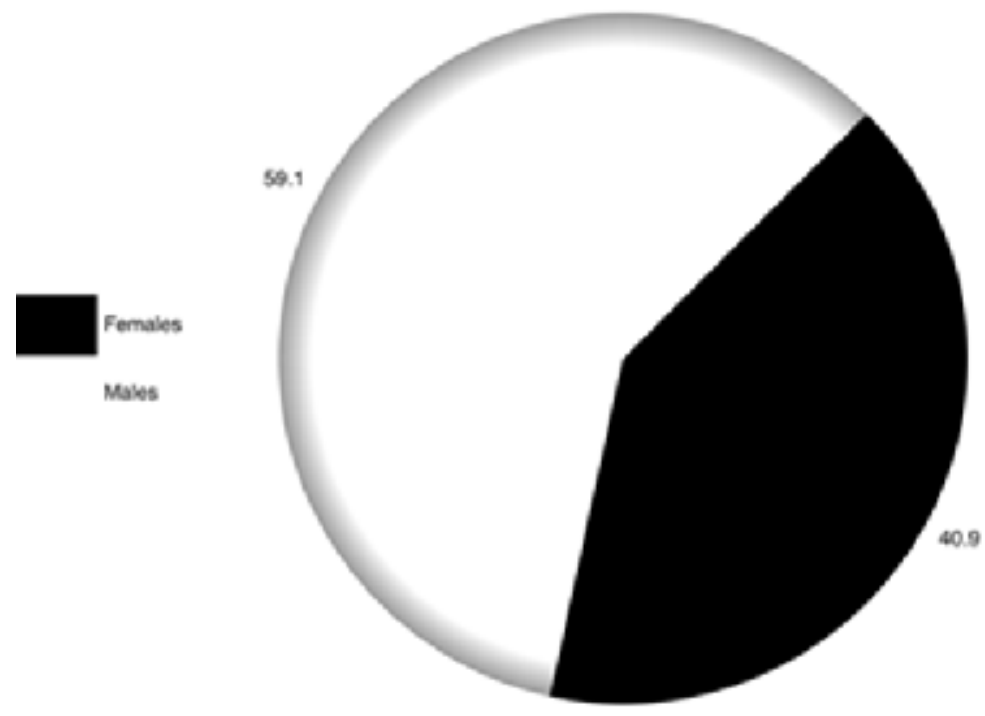

Figure 1.2 Percentage of Male and Female Obituaries

In addition to these statistics, the analysis of the content shows a conspicuous trend that is; the content of males' obituaries is much richer in detail and projection than those of females. The evaluated data explicitly shows that the obituaries announcing the deaths of females are shorter in comparison to the obituaries authored for the departed males. Female obituaries in general, are without professional and educational qualifications or achievements which are normally and explicitly stated in almost all male obituaries. Also, a tendency of disguising the names of the departed females is prevalent. Unlike the departed males who are mentioned using their personal identities, females are generally recognized in relation to their ancestral kin networks and familial patronage. They are commonly referred to as mothers, wives and sisters of their male family members. Finally, the discrepancies mentioned are not limited to a certain number of obituaries but were observed as a general prevailing trend.

The emerged actuality obliged researchers to probe the whys and wherefores behind this proclivity. Is there any kind of an established shared societal understanding that constitutes certain parameters which influence the overall shape and content of obituary announcements? To elicit an answer to this query, ten people involved in writing and publishing of the obituaries of their kith and kin were interviewed. Their responses were sought against the questions which revolved 
around the concept of gender discrimination in general and the post-death scenarios in specific. The interview responses acknowledge the presence of religious factors, social customs, family traditions, class differences, women' economic dependency on men and women's limited roles and representation in overall social and economic activities as major factors behind the lower representation and projection of females in their death announcements.

\section{Discussion and Conclusion}

The results tally with the researchers' alternative hypothesis. The situation is clearly partial towards the male segment of Pakistani society. However, based on the responses of the participants, the researchers consider that this scant attention towards females cannot be termed discriminatory. It is simply the males' situational advantage. The less projected representation of women in the Pakistani obituarial literature is empirically as well as abstractly a multidimensional phenomenon. To get a clearer picture, both genders' lives should be studied in their entirety, keeping in view their familial, communal and national cultural values and social moorings. Economic responsibilities and religious perceptions attached to both genders must also be considered.

The thrust of the participants' responses is that women's representation and projection in Pakistani newspaper obituaries is based on the roles they play and the activities they perform in given or provided situations. For example, if there are fewer obituaries representing professional women as compared to men, it doesn't mean that the society is hostile towards working women or that their left-behinds want to hide this from other people. In reality, most of the interviewees believe that based on the cultural values and family traditions, Pakistani women are not compelled or expected to play occupational roles. Generally in Pakistan, "work participation by females is considered prestige reducing rather than prestige enhancing" (Hakim and Aziz, 1998, p.735).

The identification of women in relation to their familial roles or relationships is also not something strange to the study participants. It is observed from their conversations that most of the Pakistanis do not like their women to be recognized by their names out of their family circles. Based on their religious preaching and socio-cultural values, the Pakistani society encourages its female folks to perform the role of a good mother and housewife within the four walls of the house rather than to go out to work. Even for women themselves, observed Hakim and Aziz (1998, p.734), the paternal or maternal role has always been of a very high priority. In return, cultural values prescribe the mother's position as one demanding respect, veneration and obedience from children. Religious teachings lend full support to these values too, resulting in well-known sayings and beliefs such as 'heaven lies under the mother's feet'.

Regarding the lack of females' photographs, all the interviewees believe that the tradition of 'Purdah' (seclusion and hiding of women from men) is behind this reason. Some people also consider this seclusion as a kind of a religious obligation and believe that "Purdah" enhances the respectability of women. Generally, people in Pakistan do not like strangers to look at the faces of their female relatives. The majority of the families in Pakistan continue following this tradition even after the death of their female members. Also, it should be kept in mind that according to the results, the lack of photographs is not female specific only. It is more or less a general tendency as the majority of obituaries of males are also without photographs. Hence, the researchers believe that it is not an issue of gender discrimination.

It can be inferred from the discussion that obituaries as a societal discourse reflect the values, norms and constraints prevalent in a society. Whatever belief systems or socio-cultural values there are in a society, they will be reflected in all discourses in general. Obituary is no exception. So the obituaries that constitute the data of this study also reflect the trends found in the society. Biases or traces of discrimination between two genders are not obituary specific but they are, irrespective of legitimacy and fairness criteria and debate, a continuation of the preferences and prejudices, established by traditions or privileges or religious beliefs, being practiced by the society. So traces of discrimination found in Pakistani obituaries are not intrinsic to the genre of obituary but are a reflection of local traditions, Islamic beliefs and class distinctions and orientations prevalent in the socio-cultural and religious settings of Pakistani society. From the general social perspective, in spite of the rapid and glaring progress because of the political and constitutional maneuvers in the last two decades towards gender parity, on its way to maturity, social and community oriented attitudes still lag behind. Socio-cultural dogmas and religious constraints, true or perceived or misinterpreted, still try to attach the concept of frailty to women and there are evidences of women not being at par with men not only in domains of life but also in the post-death scenario of obituaries.

\section{References}

Alam, A. (2011). Impact of Gender Discrimination on Gender Development and Poverty Alleviation. Sarhad J. Agric, 27(2), 330-331.

Delavande, A., \& Zafar, B. (2013). Gender Discrimination and Social Identity: Experimental Evidence from Urban Pakistan. Mimeo.

Eid, M. (2002). The world of obituaries: Gender across cultures and over time. Wayne State University Press.

Hakim, A., \& Aziz, A. (1998). Socio-cultural, Religious, and Political Aspects of the Status of Women in Pakistan. The Pakistan Development Review, 727-746. 
Halbur, B. \& Vandagriff, M. (1987). Societal Responses after Death: A study of Sex Differences in Newspaper Death Notices for Birmingham, Alabama, 1900-1985. Sex Roles, 17 (7/8), 421-436.

Haley, W. (1977). Journalism: Rest in Prose: The Art of the Obituary. The American Scholar, 46(2), 206-211.

Iqbal, H., Afzal, S., \& Inayat, M. (2012). Gender Discrimination: Implications for Pakistan Security. IOSR Journal of Humanities and Social Science. 1 (4), 16-25.

Kastenbaum, R., Peyton, S. \& Kastenbaum, B. (1976). Sex Discrimination after Death. Omega--Journal of Death and Dying, 7 (4), 351-359.

Kearl, M. C. (1986). Death as a Measure of Life: A Research Note on the Kastenbaum-Spilka Strategy of Obituary Analyses. Omega--Journal of Death and Dying, 17 (1), 65-78.

Maududi, S. Abu A'La (1987). Purdah and Status of Women in Islam. Islamic Publications Lahore.

Maybury, K. K. (1995). Invisible Lives: Women, Men and Obituaries. Omega-Journal of Death and Dying, 32 (1), 2737.

Moses, R. A. \& Marelli, G. D. (2004). Obituaries and the Discursive Construction of Dying and Living. Texas Linguistic Forum, 47, 123-130.

Mumtaz, Z., Salway, S., Waseem, M., \& Umer, N. (2003). Gender-based Barriers to Primary Health Care Provision in Pakistan: The Experience of Female Providers. Health policy and planning, 18(3), 261-269.

Ogletree, S. M., Figueroa, P. \& Pena, D. (2005). A Double Standard in Death? Gender Differences in Obituaries. Omega-Journal of Death and Dying, 51(4), 337-342.

Rodler, C., Kirchler, E. \& Hôlzl, E. (2002). Gender Stereotypes of Leaders: An Analysis of the Contents of Obituaries from 1974 to 1998. Sex Roles, 5 (11-12), 827- 843.

Spilka, B., Lacey, G. \& Gelb, B. (1979). Sex Discrimination after Death: A Replication, Extension and a Difference. Omega--Journal of Death and Dying, 10 (3), 227-233.

USAID (2011-12). Pakistan Education Statistics: Report. Retrieved from http://knowledge portal.pakteachers.org/sites/knowledgeportal.pakteachers.org/files/STATISTICS/Education\%20Census\%20Data/Pakist an\%20Education\% 20Statistics\%202010-11.pdf

World Bank (2001). Engendering Development: Through Gender Equality in Rights, Resources, and Voice. Oxford University Press. 